\title{
Foreword by Andrea Camanzi
}

The invitation of the editors to provide this foreword, in my capacity as President of the Italian Transport Regulation Authority in its first years of operation, came as a seal to the completion of my mandate. Yet, my pleasure in responding to it goes beyond my connection with the institution, for technology and emerging patterns of mobility disclose novel paths for the application of benchmarking in transport regulation, which compel ongoing research.

Although, over the past few years, some European countries have established or redefined the competencies of independent economic regulators with functions similar to those entrusted to the Italian authority, certain tasks pertaining to the regulation of access to infrastructure and services and the setting of levels of quality and rights of users remain unique to it. At their core lies a duty to guarantee that the conditions placed on companies to access rail, port, airport and motorway networks as well as to operate transport and mobility services for goods and passengers, are fair and non-discriminatory and that they are defined based on methodologies which create incentives for fostering competition, production efficiency and containment of costs to the benefit of users, companies and consumers. Thereby, the authority has been entrusted with the mandate to deal with major horizontal economic issues concerning all modes of transport.

In the pursuit of this task, the governing body of the authority decided from the outset to set up an Advisory Board to be composed of academics and experts from various European countries whose area of interest included modelling the frontiers of efficiency to be reached by transport companies: a sector that, both in Italy and elsewhere, remains widely characterised by competition for the market and concentration, and that, against a background of progressive opening and liberalisation under EU law, also remains intensely national. Among the members of the board have been the authors of this book.

However, the work presented in this volume reaches beyond that of the Advisory Board. It provides perspective for readers, academics and practitioners alike, with a unique stocktaking exercise of the application of benchmarking in transport in Italy and other European countries and with wide-ranging empirical evidence. The latter substantiates, among others, the need for measuring the impact of individual policy decisions over the economics of concessions and public service contracts. While such decisions pertain to the 
executive and awarding authorities, providing a metric for production efficiency and containment of costs rests with economic regulators.

Today, the digital economy, which is global in nature and disintermediates production processes, confronts regulators with new challenges. In transport, the reorganisation of the demand-supply relationship in mobility services that is under way, and which is underpinned by platforms and web applications, while creating positive externalities for network infrastructures, also modifies the traditional role and strategic choices of companies, which increasingly diversify and adapt their operations.

Such developments enhance the need for regulators to avail themselves of advanced and dynamic methods for measuring costs and benefits and their distribution among the actors of the new value chain, while ensuring protection of intermediate users and guaranteeing the freedom of customers to make their choices. In this perspective, existing benchmarking methodologies provide a fundamental basis from which to pursue further research and testing. Data-driven regulation relying on artificial intelligence and the Internet of Things, which generate online structured flows of data and are able to feed demand forecasts in ways which are unprecedented, opens up new avenues for the application of benchmarking in transport.

Andrea Camanzi

President of the Italian Transport Regulation Authority, 2013-2020

Rome, November 2020 